\title{
Análise da Progressividade da Carga Tributária sobre a População da Região Sul do Brasil*
}

\author{
Tax Burden Progressivity Analysis \\ on the Brazil Southern Population
}

\author{
Denize Mirian da Silva** \\ José Adrian Pintos-Payeras***
}

Resumo: O presente artigo apresenta um estudo da atual incidência da carga tributária nos estados da região Sul do Brasil. Para estimar a carga tributária, foi utilizado o modelo desenvolvido na tese de doutorado "A carga tributária no Brasil e sua distribuição" por José Adrian Pintos Payeras no ano de 2008. A base de dados é composta pelos microdados da Pesquisa de Orçamentos Familiares (POF) de 2008-2009 em conjunto com a legislação tributária federal e das Unidades da Federação que compõem essa região do país. Os resultados mostram que a carga tributária direta é progressiva quando levada em consideração a ordenação da renda familiar per capita, conforme mostra o índice de Lerman-Yitzhaki. Porém, o Imposto sobre a Propriedade Predial e Territorial Urbana (IPTU) é regressivo. Ao analisar os tributos indiretos verificou-se que eles são regressivos quando tomada como base tanto a renda como a despesa monetária das famílias. O Imposto sobre Operações relativas à Circulação de Mercadorias e sobre Prestações de Serviços de Transporte Interestadual e Intermunicipal e de Comunicação (ICMS) é o tributo que tem maior participação na carga tributária indireta sobre as famílias, e a Contribuição para Financiamento da Seguridade Social (Cofins) é o mais regressivo. Após a análise comparativa deste estudo com outro elaborado com base na POF 2002-2003, constatou-se que houve um leve aumento na carga tributária indireta média para a região Sul do Brasil.

Palavras-chave: Capacidade de pagamento. Carga tributária. Regressividade.

\begin{abstract}
The main objective of this paper is to present a study of current tax burden distribution in the Southern states of Brazil. For this, it was used the model developed in the doctoral thesis "A carga tributária no Brasil e sua distribuição" by José Adrian Pintos Payeras. The database is composed by Household Budgeting Survey (POF) 20082009 microdata, considering the tax regulations of the country and southern states. The Lerman-Yitzhaki index shows that the direct tax burden is progressive, when taken into account the per capita household income ordering. However, municipal tax on properties (IPTU) is regressive. Indirect taxes are regressive when taking from both: the income and

\footnotetext{
* Os autores agradecem ao Conselho Nacional de Desenvolvimento Científico e Tecnológico (CNPq) pelo financiamento do projeto de pesquisa e a Coordenação de Aperfeiçoamento de Pessoal de Nível Superior (Capes) pela bolsa concedida.

* * Doutoranda em Economia Aplicada pelo Programa de Pós-Graduação em Economia (PPGE) da Faculdade de Economia, Administração e Contabilidade de Ribeirão Preto (FEA-RP) da Universidade de São Paulo (USP). E-mail: denize.msilva@hotmail.com de Economia da Universidade Estadual de Londrina (UEL).E-mail adrian@uel.br
}

*** Doutor em Economia Aplicada pela Universidade de São Paulo (USP). Professor do Departamento
\end{abstract}


the monetary expenditure base. ICMS (value added tax) has increased participation in the indirect tax burden and the most regressive is the Cofins (Social Security Financing). The comparative analysis of studies based on POF 2002-2003 with the present study showed that there was a slight increase in the average indirect tax burden in the Brazilian Southern region.

Keywords: Ability to pay. Tax burden. Regressivity.

JEL Classification: H31; H22; D31.

\section{Introdução}

No Brasil, os debates para uma reforma tributária abrangem as três esferas do governo. No âmbito federal, em 2007, começou a circular no congresso a Proposta de Emenda à Constituição (PEC) 31/2007, e desde então foram anexadas 16 propostas a ele. De acordo com a Cartilha sobre a Reforma Tributária, elaborada pelo Ministério da Fazenda (BRASIL, 2008), entre os objetivos principais dessa PEC estão a simplificação do Sistema Tributário Nacional, a desoneração tributária, o combate à guerra fiscal entre os estados e também à sonegação fiscal. A última ação legislativa ocorreu em 2008, deferindo-o para aprovação no plenário, e nos últimos quatro anos não houve nenhuma definição a respeito.

Nos estados da região Sul do Brasil, a reforma mais recente implantada foi no Paraná. A intitulada minirreforma tributária ${ }^{1}$ começou a vigorar em 2009 por meio da Lei n. ${ }^{\circ} 16.016$ e houve todo um discurso por parte do governo desse estado, afirmando que as alterações propostas iriam contribuir para a redução significativa das desigualdades na distribuição de renda. Porém, segundo Pintos-Payeras, Silva e Carvalho (2011), as mudanças nas alíquotas não reduziram a regressividade dos tributos sobre os alimentos, sendo que esses produtos são de primeira necessidade e comprometem boa parte do orçamento das famílias.

É em meio a discussões para uma reforma tributária nacional e estudos que mostram que a tributação tem papel fundamental na concentração de renda que se insere este trabalho. Este estudo analisará, com base nas informações da POF (Pesquisa de Orçamentos Familiares) 2008-2009, como os tributos são distribuídos entre diferentes estratos de renda da população da região Sul do Brasil, tomando como base a renda, no caso dos tributos diretos, e a renda e a despesa total das famílias na mensuração da carga tributária indireta. Para tal, será utilizado o modelo desenvolvido por Pintos-Payeras (2008). No intuito de determinar se um tributo é progressivo ou regressivo, será utilizado o índice desenvolvido por Lerman e Yitzhaki (1995). Dessa forma, será possível verificar a incidência tributária no ren-

$1 \quad$ Basicamente reduziu as alíquotas do ICMS de 18\% e 25\%, para 12\%, sobre alimentos, medicamentos, eletrodomésticos e produtos de higiene e aumentou a alíquota de $26 \%$ para $28 \%$ deste imposto para gasolina, álcool e de $27 \%$ para $29 \%$ sobre energia elétrica, telefonia, cigarro e bebidas alcoólicas. 
dimento monetário e no padrão de consumo das famílias e qual o impacto que os tributos acarretam na distribuição de renda nessa região do país. Com o estudo, as autoridades estarão munidas de informações relevantes que podem ser utilizadas para tornar a tributação mais progressiva para a população.

Este artigo está dividido em quatro seções, além desta introdução. Na seção 2, são feitos os comentários sobre a base de dados e problemas metodológicos. $\mathrm{Na}$ seção 3, apresentam-se as estimativas da carga tributária direta e indireta. Por fim, na seção, 4, apresentam-se as considerações finais do estudo.

\section{Base de Dados e Método}

Pintos-Payeras (2008) estimou a carga tributária a partir dos microdados da POF de 2002-2003 (IBGE, 2009) e da legislação tributária federal, dos estados e dos municípios. O presente artigo seguiu os mesmos procedimentos metodológicos sugeridos pelo referido autor para estimar a carga tributária para os estados da região Sul do Brasil com base na POF 2008-2009 (IBGE, 2009).

A carga tributária direta, aquela incidente sobre o rendimento e o patrimônio das famílias, foi obtida a partir das informações declaradas na POF de 2008-2009. No rol de tributos ${ }^{2}$ averiguados em tal pesquisa estão: Imposto de Renda (IR), Instituto Nacional do Seguro Social (INSS) (contribuição à previdência social), Imposto Predial e Territorial Urbano (IPTU), Imposto sobre Propriedade de Veículos Automotivos (IPVA), contribuição sindical, taxas de conselhos e associações de classe, Imposto Territorial Rural (ITR), Serviço de Patrimônio da União (SPU), Imposto de Transmissão de Bens Imóveis (ITBI), emplacamento, taxa do Departamento de Trânsito (Detran) e exame psicotécnico. Os dados incompatíveis foram excluídos. Como incompatíveis foram consideradas as informações em que a carga tributária era maior do que a renda familiar. Nesses casos, há grande probabilidade de ter ocorrido a subdeclaração da renda ou erros de medida.

No cálculo das medidas de progressividade foi considerada a ordenação das pessoas conforme a renda familiar per capita, divididas em 13 estratos. Essa forma permite analisar mais detalhadamente como progride a carga tributária conforme o nível de renda.

Foi levada em consideração a carga tributária indireta sobre a renda e sobre a despesa total das famílias. Segundo Creedy (1998), a progressividade dever ser medida em termos da despesa total e a poupança nada mais é que o consumo

2 Os tributos são uma obrigação paga pelos contribuintes à administração pública e são divididos em três modalidades: 1) impostos: destinados para custear a máquina pública (IR, ICMS etc.); 2) taxa: cobrança que tem como contrapartida a prestação de algum serviço (taxa de iluminação pública etc.); 3) contribuições: possui alguma destinação específica para um determinado grupo ou atividade (INSS, Cofins etc.). 
futuro, o qual também será tributado. Se as famílias tomam como base a renda vitalícia esperada para determinar o seu dispêndio, então o consumo é uma medida mais elaborada dos recursos vitalícios do que a renda anual (POTERBA, 1989).

No Brasil, há um grande número de tributos indiretos. Neste artigo, optou-se pelos seguintes: ICMS, Imposto sobre Produtos Industrializados (IPI), Programa de Integração Social (PIS) e Contribuição para Financiamento da Seguridade Social (Cofins). Esses quatro tributos indiretos selecionados foram responsáveis por aproximadamente 37\% da arrecadação total em 2013 (BRASIL, 2014).

Como se sabe, cada estado tem suas próprias normas para o ICMS. Essas informações foram obtidas nos sites das Secretarias de Fazenda dos estados da região Sul do Brasil. As alíquotas, isenções e reduções de base do ICMS adotadas na estimação seguiram o regulamento do ICMS (RICMS) vigente em 2011 em cada um desses estados.

Para tornar factível a proposta de analisar a carga tributária em cada Unidade da Federação da região Sul do Brasil, foi preciso adotar o pressuposto simplificador de que incide sobre o produto apenas a alíquota determinada no estado, ou seja, foi admitido que o produto é produzido e vendido dentro do estado. Embora seja uma limitação relevante desconsiderar o fluxo entre os estados, essa será a forma de identificar a carga dos tributos indiretos conforme a legislação do RICMS de cada estado. Do contrário, teria que ser escolhido um estado como sendo representativo dos demais e aplicar suas normas para toda a região Sul. Como as alíquotas e isenções diferem entre os estados, uma análise desse tipo não permite identificar as diferenças de progressividade entre as Unidades Federativas.

Devido à necessidade de conhecer a composição do medicamento para saber se ele é isento de ICMS e dado que a POF não apresenta o nome genérico, foi considerado no estudo que o ICMS incide sobre todos os medicamentos, exceto aqueles para o tratamento da AIDS e os quimioterápicos para tratamento de câncer. Isso pode levar, neste caso, a uma superestimação da carga tributária sobre medicamentos.

Para simplificar a análise do PIS e da Cofins, foi considerado, sempre que a legislação permitiu, que os produtores dos bens e serviços foram optantes pelo regime de incidência não cumulativa. ${ }^{3}$ Nesses casos, as alíquotas da contribuição para o PIS/Programa de Formação do Patrimônio do Servidor Público - (Pasep) e da Cofins são, respectivamente, de 1,65\% e de 7,6\%. Foram considerados os casos especiais desses tributos na estimação, tais como as alíquotas reduzidas a zero dos produtos hortícolas e frutas $\mathrm{e}^{4}$ as alíquotas incidentes sobre energia elétrica em cada estado. No caso dos serviços, foi considerado o regime de incidência cumu-

\footnotetext{
3 Para o PIS/Pasep a não cumulativa foi instituída pela Lei $n^{\circ} 10.637 / 2002$, e para a Cofins pela Lei $\mathrm{n}^{\circ} 10.833 / 2003$.

4 Previstas na Lei $\mathrm{n}^{\circ}$ 10.865/2004, artigo 28.
} 
lativa dessas contribuições e que só há uma etapa de produção e comercialização, o que é uma generalização bastante razoável no caso dos serviços adquiridos pelas famílias. Nesse último regime, a alíquota do PIS/Pasep é 0,65\% e a alíquota da Cofins é 3\%.

As alíquotas do IPI seguiram a disposição da Tabela de Incidência do Imposto sobre Produtos Industrializados (TIPI), de acordo com a versão de 2012.

\subsection{Análise da Progressividade}

Para averiguar a progressividade dos tributos, foi usado o índice desenvolvido por Lerman e Yitzhaki (1995), que toma como base o ordenamento da renda final, isto é, a renda após a incidência do tributo ou do benefício. A justificativa para o uso do índice de Lerman-Yitzhaki é que deve ser levada em consideração a possibilidade de um tributo afetar a reordenação das rendas. Índices de progressividade, como o de Kakwani, que usam a ordenação da renda inicial, desconsideram a "[...] possibilidade de a ordenação das rendas finais ser diferente das rendas iniciais” (HOFFMANN, 2007, p. 180). ${ }^{5}$

Sendo $G z$ o índice de Gini da renda final e $C_{Z}^{*}$ a razão de concentração do tributo, definida com base na ordenação da renda final, o índice Lerman-Yitzhaki, $\pi_{L Y}$, para esse tributo, é:

$$
\pi_{L Y}=C_{Z}^{*}-G_{Z}
$$

Valores positivos indicam que o tributo é progressivo e valores negativos indicam que o tributo é regressivo. Foi utilizada a ordenação da renda familiar per capita para encontrar o índice de Lerman-Yitzhaki.

\subsection{Estimação da Carga Tributária}

No presente estudo, constam dois tipos de tributos indiretos: aqueles para os quais a alíquota prevista em lei coincide com a taxa efetiva, $a$, e aqueles para os quais a alíquota é diferente da taxa efetiva, $A$. Quando a alíquota prevista em lei é aplicada sobre o valor da nota fiscal, há uma diferença entre alíquota e taxa. Dos tributos indiretos considerados, apenas no caso do IPI a alíquota coincide com a taxa, pois a alíquota é aplicada sobre o valor livre de tributos. Para os demais (ICMS, PIS e Cofins), as alíquotas não coincidem com a taxa efetiva.

$5 \quad$ Para mais detalhes, ver Lerman e Yitzhaki (1995), Hoffmann (2007), neste artigo o "índice de Lerman-Yitzhaki" foi denominado "índice de Kakwani modificado"; em Hoffmann (2009) já foi usada a denominação "índice de Lerman-Yitzhaki". 
Definindo $d$ como o valor da despesa, $A$ a alíquota do(s) tributo(s) que incide(m) sobre $d$ e $a$ como a(s) alíquota(s) do(s) tributo(s) que incide(m) sobre o valor $(x)$ da despesa antes dos tributos, esse valor é:

$$
x=\frac{d\left[1-\sum A\right]}{\left(1+\sum a\right)}
$$

Para o caso dos tributos indiretos considerados, o somatório do numerador é formado pelas alíquotas dos seguintes tributos: ICMS, PIS, Cofins. O somatório do denominador é formado apenas pelo IPI.

O valor dos tributos indiretos considerados, em unidades monetárias, é dado por:

$$
t=d-x
$$

A taxa dos tributos indiretos, $r$, é obtida por:

$$
r=\frac{t}{x}
$$

O resultado desta equação é a carga tributária indireta efetiva. Para o ICMS, o PIS e a Cofins é verificado que $r>A$, e para o IPI tem-se $r=a$.

A carga sobre o valor da despesa, $r_{d}$, é:

$$
r_{d}=\frac{t}{d}
$$

Note-se que com simples manipulação algébrica, usando (3), (4) e (5), é possível verificar que:

$$
r=\frac{r_{d}}{1-r_{d}}
$$

O valor em unidades monetárias do ICMS, o qual incide sobre o faturamento, é obtido pela multiplicação do valor da despesa pela respectiva alíquota, $A_{I C M S}$ :

$$
I C M S=d\left(A_{\text {ICMS }}\right)
$$

A taxa efetiva do ICMS, ressaltando que o ICMS incide sobre o valor da Nota Fiscal, é obtida por:

$$
r_{I C M S}=\left(\frac{I C M S}{x}\right) 100
$$


O valor em reais do PIS é dado por:

$$
P I S=d\left(A_{P I S}\right)
$$

A taxa efetiva do PIS é obtida por:

$$
r_{P I S}=\left(\frac{P I S}{x}\right) 100 .
$$

O valor em reais da Cofins é dado por:

$$
\text { COFINS }=d\left(A_{\text {COFINS }}\right)
$$

A taxa efetiva da Cofins é obtida por:

$$
r_{\text {COFINS }}=\left(\frac{\text { COFINS }}{x}\right) 100 .
$$

O IPI é obtido multiplicando-se o valor da despesa antes dos tributos pela sua alíquota, $a_{I P I}$, isto é:

$$
I P I=x\left(a_{I P I}\right) .
$$

Note que este é o único entre os tributos indiretos considerados, em que $r=a$.

Percebe-se que as taxas efetivas do ICMS, PIS e da Cofins acabam sendo maiores do que a alíquota prevista pela lei.

Como deve estar claro, há uma diferença na forma com que está sendo apurada a tributação direta e a indireta. A direta, por se basear nas informações da POF de 2008-2009, além de seguir as regras tributárias da época, é uma estimação da carga tributária efetiva. Já a carga tributária indireta é a potencial, ou seja, a que deveria ser paga seguindo regras mais atuais dos tributos indiretos. Por esse motivo, optou-se, no presente trabalho, tratar a carga tributária direta separadamente da indireta.

\subsection{Base de Dados}

A POF de 2008-2009 investigou 56.091 famílias no Brasil, sendo que destas, 6.731 pertencem à região Sul e compõem a amostra do presente estudo. Os dados incompatíveis foram excluídos, conforme ressaltado anteriormente. 
A Tabela 1 apresenta as características de cada classe de renda familiar selecionada. Analisando o primeiro estrato é possível verificar que $10,71 \%$ das pessoas receberam até 2 salários mínimos (SM) e 48,55\% da população da região Sul do Brasil recebeu até 5 salários mínimos e detinha 20,39\% da renda total. Já a classe de maior renda, com $2,66 \%$ das pessoas, detinha $17,43 \%$ da renda total no período da pesquisa.

Tabela 1 - Região Sul do Brasil: pessoas, famílias e renda familiar média para as 10 classes selecionadas, excluindo os dados incompatíveis

\begin{tabular}{|c|c|c|c|c|c|c|}
\hline $\begin{array}{l}\text { Classes de Ren- } \\
\text { da Familiar } \\
(\mathrm{SM})^{(1)}\end{array}$ & Pessoas ${ }^{(2)}$ & $\begin{array}{l}\% \text { das } \\
\text { Pes- } \\
\text { soas }\end{array}$ & $\begin{array}{l}\text { Renda } \\
\text { Familiar } \\
\text { Média }\end{array}$ & $\begin{array}{c}\% \text { da } \\
\text { Renda } \\
\text { Familiar }\end{array}$ & Famílias & $\begin{array}{c}\% \text { das } \\
\text { Fami- } \\
\text { lias }\end{array}$ \\
\hline Até $2 \mathrm{SM}$ & 2.934 .730 & 10,71 & 569,16 & 2,43 & 1.154 .766 & 13,07 \\
\hline Mais de 2 a 3 SM & 3.616 .426 & 13,20 & $1.041,49$ & 4,81 & 1.252 .333 & 14,18 \\
\hline Mais de 3 a 5 SM & 6.753 .595 & 24,64 & $1.634,47$ & 13,15 & 2.179 .419 & 24,67 \\
\hline Mais de 5 a 6 SM & 2.681 .031 & 9,78 & $2.284,06$ & 6,79 & 805.551 & 9,12 \\
\hline Mais de 6 a 8 SM & 3.720 .720 & 13,58 & $2.863,40$ & 11,87 & 1.123 .361 & 12,72 \\
\hline Mais de 8 a 10 SM & 1.926 .477 & 7,03 & $3.699,89$ & 8,10 & 593.541 & 6,72 \\
\hline $\begin{array}{l}\text { Mais de } 10 \text { a } 15 \\
\text { SM }\end{array}$ & 2.854 .797 & 10,42 & $5.037,79$ & 15,80 & 849.822 & 9,62 \\
\hline $\begin{array}{l}\text { Mais de } 15 \text { a } 20 \\
\text { SM }\end{array}$ & 1.222 .875 & 4,46 & $7.118,53$ & 9,19 & 349.669 & 3,96 \\
\hline $\begin{array}{l}\text { Mais de } 20 \text { a } 30 \\
\text { SM }\end{array}$ & 965.917 & 3,52 & $9.900,18$ & 10,44 & 285.844 & 3,24 \\
\hline Mais de $30 \mathrm{SM}$ & 730.211 & 2,66 & $19.796,63$ & 17,43 & 238.525 & 2,70 \\
\hline $\begin{array}{l}\text { Região Sul do } \\
\text { Brasil }\end{array}$ & 27.406 .780 & 100,00 & $3.067,94$ & 100,00 & 8.832 .830 & 100,00 \\
\hline
\end{tabular}

Fonte: Elaboração própria com base nos microdados da POF de 2008-2009 (IBGE, 2009).

Notas: ${ }^{(1)}$ Seguindo a data de referência da POF de 2008-2009 (IBGE, 2009), considerou-se o salário mínimo de $\mathrm{R} \$ 415$, vigente em 15 de janeiro de 2009; ${ }^{(2)}$ Aplicou-se o fator de expansão da amostra.

\section{Estimação da Carga Tributária}

Nesta seção, consta a estimação da carga tributária, por estrato de renda, com base na renda e na despesa das famílias e também dos índices de Gini e Lerman-Yitzhaki. Na primeira subseção, constam os resultados para a carga tributária direta e na segunda, para a carga tributária indireta. 


\subsection{Carga Tributária Direta}

Na Tabela 2, consta a carga tributária direta, considerando a renda per capita para 13 classes de renda selecionadas. É possível notar que, apesar do valor gasto com o pagamento desses tributos aumentar na mesma direção da renda para a maioria dos estratos, quando é analisada a carga direta como percentual da renda per capita, esse comportamento não é observado. Nesse quesito, as famílias com rendimento de mais de $8 \mathrm{SM}$ a $11 \mathrm{SM}$ são as mais oneradas, seguidas das famílias dos estratos com mais de 11SM a 16SM e mais de 6SM a 8SM. Elas destinam $10,88 \%, 7,69 \%$ e $7,52 \%$, respectivamente, da sua renda ao pagamento dos tributos diretos. Nenhum dos tributos selecionados é monotonicamente crescente. ${ }^{6}$

A carga tributária direta per capita sobre as famílias da região Sul do Brasil tem uma taxa média de 6,56\%. Dos tributos destacados na Tabela 2, o relacionado com a previdência pública foi o que apresentou a maior carga média, $2,56 \%$.

Uma informação que chama a atenção é a carga tributária direta de 4,08\% sobre o primeiro estrato de renda familiar. Como se vê, grande parte disso deve-se ao IPTU e à previdência pública. O IPTU, que é um tributo sobre patrimônio, onera proporcionalmente mais as famílias da primeira classe de renda do que as famílias da última, mostrando-se regressivo quando comparadas essas duas faixas. A taxa do IPTU para os três primeiros estratos de renda está acima da média nacional, que é de $1,09 \%$. A regressividade desse tributo é confirmada pelo índice de Lerman-Yitzhaki, que é igual a -0,1447.

O IPVA e o IR são progressivos, com respectivos índices de Lerman-Yitzhaki de 0,03 e 0,36, aproximadamente. A contribuição para o INSS é neutra, ou seja, apresentou índice de progressividade próximo de 0 . A carga tributária direta é progressiva para a região Sul do Brasil, isto é, os tributos diretos contribuem para reduzir a desigualdade. Como mostra Hoffmann (2007), a mudança no índice de Gini decorrente do tributo pode ser decomposta em uma parcela proporcional ao índice de Lerman-Yitzhaki e em um efeito da reordenação. O índice de Gini, calculado com base na ordenação da renda familiar per capita é, no Sul do Brasil, $0,5006.7$ Ao deduzir os tributos diretos da renda familiar per capita, obtém-se um índice de Gini de 0,4960.

6 Aumenta invariavelmente conforme o aumento da renda.

7 Calculado com base na POF de 2008-2009 sem as informações incompatíveis.

SILVA, D. M.; PINTOS-PAYERAS, J. A. Análise da Progressividade da Carga Tributária... 
Tabela 2 - Região Sul do Brasil: carga tributária direta sobre a renda familiar per capita

\begin{tabular}{|c|c|c|c|c|c|c|c|}
\hline $\begin{array}{l}\text { Classes de Renda } \\
\text { Familiar }\left(\text { em SM) }^{(1)}\right.\end{array}$ & $\begin{array}{l}\text { Renda } \\
\text { familiar } \\
\text { per } \\
\text { capita } \\
\text { (R\$) }\end{array}$ & $\begin{array}{c}\text { Tri- } \\
\text { buto } \\
\text { direto } \\
\text { total } \\
\text { (R\$) }\end{array}$ & $\begin{array}{c}\text { Carga } \\
\text { direta } \\
\text { per } \\
\text { capita } \\
\text { (\%) }\end{array}$ & $\begin{array}{l}\text { IPTU } \\
\text { (\%) }\end{array}$ & $\begin{array}{l}\text { Previ- } \\
\text { dên- } \\
\text { cia } \\
\text { Públi- } \\
\text { ca (\%) }\end{array}$ & $\begin{array}{l}\text { IPVA } \\
\text { (\%) }\end{array}$ & IR (\%) \\
\hline Até $1 / 2 \mathrm{SM}$ & 146,19 & 5,97 & 4,08 & 1,63 & 1,56 & 0,36 & 0,02 \\
\hline $\begin{array}{l}\text { Mais de } 1 / 2 \text { SM a } 1 \\
\text { SM }\end{array}$ & 311,62 & 13,87 & 4,45 & 1,26 & 1,96 & 0,48 & 0,02 \\
\hline $\begin{array}{l}\text { Mais de } 1 \text { SM a } 1 \text { e } \\
1 / 2 S M\end{array}$ & 514,50 & 26,13 & 5,08 & 1,17 & 2,47 & 0,54 & 0,13 \\
\hline $\begin{array}{l}\text { Mais de } 1 / 2 \mathrm{SM} \text { a } \\
2 \mathrm{SM}\end{array}$ & 719,70 & 38,76 & 5,39 & 1,09 & 2,68 & 0,58 & 0,19 \\
\hline Mais de $2 \mathrm{SM}$ a $3 \mathrm{SM}$ & 1015,34 & 61,08 & 6,02 & 1,32 & 2,80 & 0,67 & 0,45 \\
\hline $\begin{array}{l}\text { Mais de } 3 S M \text { a } 3 \text { e } \\
1 / 2 \text { SM }\end{array}$ & 1342,83 & 78,34 & 5,83 & 0,90 & 2,70 & 0,74 & 0,83 \\
\hline $\begin{array}{l}\text { Mais de } 3 \text { e } 1 / 2 \mathrm{SM} \\
\text { a } 4 \mathrm{SM}\end{array}$ & 1551,45 & 100,77 & 6,50 & 0,73 & 2,88 & 0,75 & 0,99 \\
\hline Mais de $4 \mathrm{SM}$ a $5 \mathrm{SM}$ & 1851,70 & 134,83 & 7,28 & 1,09 & 3,21 & 0,66 & 1,33 \\
\hline Mais de $5 \mathrm{SM}$ a $6 \mathrm{SM}$ & 2244,78 & 155,49 & 6,93 & 0,78 & 2,73 & 0,67 & 1,37 \\
\hline Mais de $6 \mathrm{SM}$ a $8 \mathrm{SM}$ & 2850,43 & 214,42 & 7,52 & 1,01 & 2,48 & 0,71 & 2,38 \\
\hline $\begin{array}{l}\text { Mais de } 8 \mathrm{SM} \mathrm{a} \\
11 \mathrm{SM}\end{array}$ & 3906,80 & 424,91 & 10,88 & 1,40 & 3,36 & 0,72 & 4,39 \\
\hline $\begin{array}{l}\text { Mais de } 11 \mathrm{SM} \text { a } \\
16 \mathrm{SM}\end{array}$ & 5465,87 & 420,40 & 7,69 & 1,07 & 1,99 & 0,61 & 3,03 \\
\hline Mais de $16 \mathrm{SM}$ & 10322,95 & 750,21 & 7,27 & 0,76 & 1,89 & 0,44 & 3,50 \\
\hline Média & 988,76 & 64,86 & 6,56 & 1,09 & 2,56 & 0,62 & 1,44 \\
\hline $\begin{array}{l}\text { Índice de Lerman- } \\
\text { Yitzhaki }\end{array}$ & & & 0,0884 & $-0,1447$ & 0,0026 & 0,0304 & $-0,3584$ \\
\hline Índice de Gini( ${ }^{(2)}$ & 0,5006 & & 0,4960 & 0,5017 & 0,5003 & 0,5004 & 0,4953 \\
\hline
\end{tabular}

Fonte: Elaboração própria com base nos microdados da POF de 2008-2009. (IBGE, 2009).

Notas: ${ }^{(1)}$ Seguindo a data de referência da POF de 2008-2009 (IBGE, 2009), considerou-se o salário mínimo de $R \$ 415$, vigente em 15 de janeiro de 2009; (2) Para a renda familiar per capita o índice de Gini foi calculado seguindo sua ordenação, para cada tributo selecionado o índice de Gini foi calculado com base na ordenação da renda familiar per capita após a dedução do tributo indicado na coluna.

\subsection{Carga Tributária Indireta}

Na Tabela 3 consta a carga tributária indireta sobre a renda. É possível verificar que o percentual da renda das famílias mais pobres comprometido com 
tributos indiretos é de 19,25\%; já os mais ricos destinam 9,17\% da renda para esse fim. Os tributos indiretos são regressivos na região Sul do Brasil. Dos tributos analisados, o que tem maior participação na carga indireta é o ICMS, seguido da Cofins. Quando é levada em consideração a tributação sobre a despesa das famílias, a carga tributária indireta onera principalmente aquelas que compõem os quatro primeiros estratos de renda. Com destaque para a classe de renda familiar de mais de 3SM a 5SM, em que a incidência dos tributos indiretos sobre a despesa familiar total é de 19,08\%.

Tabela 3 - Região Sul do Brasil: carga tributária indireta tomando como base na renda familiar, por tributo selecionado, sobre a despesa familiar total, por classe de renda (em \%)

\begin{tabular}{l|c|c|c|c|c|c}
\hline $\begin{array}{l}\text { Classes de Renda } \\
\text { Familiar (em SM) }\end{array}$ & $\begin{array}{c}\text { Carga } \\
\text { Indireta } \\
\text { sobre a } \\
\text { Renda }\end{array}$ & ICMS & PIS & Cofins & IPI & $\begin{array}{c}\text { Carga Indireta } \\
\text { sobre despesa } \\
\text { familiar total }\end{array}$ \\
\hline Até 2SM & 19,25 & 9,52 & 1,22 & 5,59 & 2,39 & 18,71 \\
Mais de 2 a 3 SM & 15,89 & 7,75 & 0,99 & 4,53 & 2,11 & 18,81 \\
Mais de 3 a 5 SM & 15,49 & 7,72 & 0,94 & 4,31 & 2,04 & 19,08 \\
Mais de 5 a 6 SM & 14,57 & 7,41 & 0,87 & 4,01 & 1,81 & 19,04 \\
Mais de 6 a 8 SM & 14,66 & 7,42 & 0,89 & 4,07 & 1,74 & 18,26 \\
Mais de 8 a 10 SM & 14,48 & 7,22 & 0,86 & 3,95 & 1,86 & 17,05 \\
Mais de 10 a 15 SM & 12,85 & 6,33 & 0,77 & 3,55 & 1,58 & 16,21 \\
Mais de 15 a 20 SM & 12,69 & 6,16 & 0,77 & 3,49 & 1,57 & 15,90 \\
Mais de 20 a 30 SM & 11,90 & 5,76 & 0,73 & 3,33 & 1,41 & 15,30 \\
Mais de 30 SM & 9,17 & 4,41 & 0,56 & 2,55 & 1,20 & 13,73 \\
Média & 13,21 & 6,52 & 0,80 & 3,67 & 1,66 & 16,83 \\
\hline
\end{tabular}

Fonte: Elaboração própria com base nos microdados da POF de 2008-2009 (IBGE, 2009).em conjunto com a legislação tributária.

Nota: ${ }^{(1)}$ Seguindo a data de referência da POF de 2008-2009 (IBGE, 2009), considerou-se o salário mínimo de $R \$ 415$, vigente em 15 de janeiro de 2009.

Pintos-Payeras (2010) estima a carga tributária indireta tomando como base a renda familiar para região Sul do Brasil, utilizando a POF 2002-2003. O Gráfico 1 mostra uma análise comparativa dos resultados obtidos nesse estudo com os da POF 2008-2009. Para as famílias com renda entre 3SM e 5SM, a carga tributária aumentou 3,68 pontos percentuais. O comportamento foi semelhante para famílias com rendimentos entre $5 \mathrm{SM}$ e $6 \mathrm{SM}$ e as que receberam entre $8 \mathrm{SM}$ e $10 \mathrm{SM}$. Nas outras classes de renda selecionadas, o percentual destinado a pagar tributos indiretos diminuiu. A redução menos expressiva foi para as famílias com renda de até 
2SM, em que a carga tributária indireta passou de 20,22\% para 19,25\% da renda. A tributação indireta média para a região Sul aumentou de 13,13\% para 13,21\%.

Gráfico 1 - Região Sul do Brasil: carga tributária indireta tomando como base a renda familiar,

levando em consideração a POF 2002-2003(1) e a POF 2008-2009 ${ }^{(2)}$.

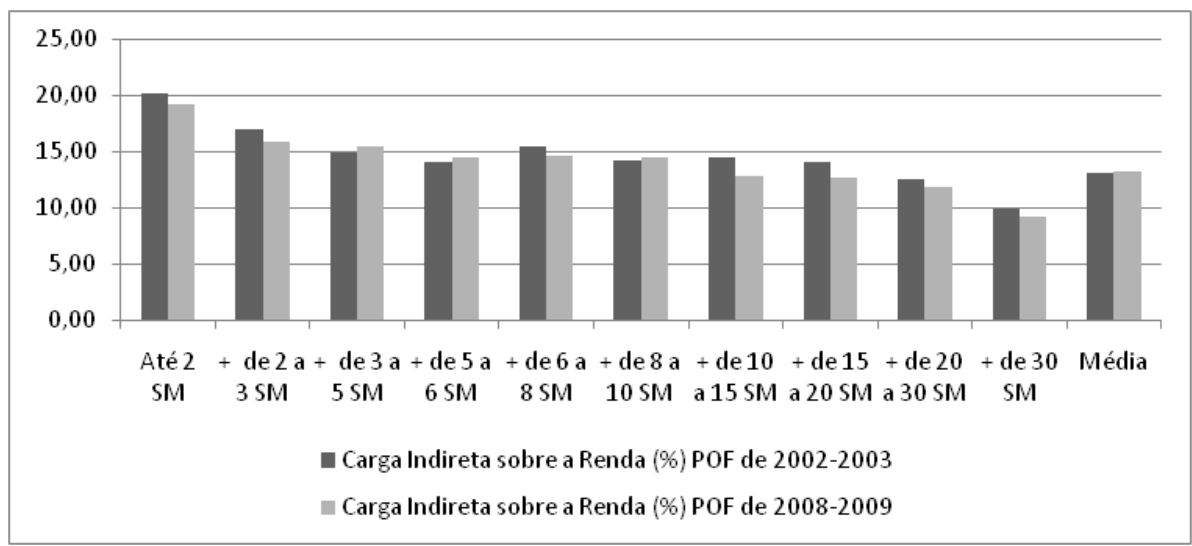

Fonte: Elaboração própria com base em Pintos-Payeras (2010) e nos microdados da POF de 2008-2009 (IBGE, 2009) em conjunto com a legislação tributária.

Notas: (1) Seguindo a data de referência da POF de 2002-2003 (IBGE, 2009), considerou-se o salário mínimo de $R \$ 400$, vigente em 15 de janeiro de 2003; ${ }^{(2)}$ Seguindo a data de referência da POF de 2008-2009 (IBGE, 2009), considerou-se o salário mínimo de R $\$ 415$, vigente em 15 de janeiro de 2009.

A Tabela 4 mostra como é composta a despesa monetária familiar para as classes de renda selecionadas. O maior dispêndio das famílias com renda de até 2SM foi com o grupo alimentos, $R \$ 181,43$, seguido de habitação, $R \$ 130,46$ e transporte, $\mathrm{R} \$ 73,18$. Já as famílias do último estrato de renda selecionado destinaram a maior parte de sua renda para gastos com transporte, $R \$ 2.911,38$, outras despesas correntes, $R \$ 2.473,32$ e aumento do ativo, $R \$ 2.421$,42. Com exceção do grupo fumo e educação, o gasto monetário com os grupos de despesa selecionados apresentou relação monotônica positiva ${ }^{8}$ com a renda.

8 Aumenta invariavelmente conforme a renda aumenta. 
Tabela 4 - Região Sul do Brasil: média do desembolso monetário mensal com os grupos de despesa, segundo as classes selecionadas

\begin{tabular}{|c|c|c|c|c|c|c|c|}
\hline $\begin{array}{l}\text { Classes de } \\
\text { Renda Fa- } \\
\text { miliar (em } \\
\text { SM)(1) }\end{array}$ & $\begin{array}{l}\text { Alimen- } \\
\text { tos }\end{array}$ & $\begin{array}{c}\text { Habita- } \\
\text { ção }\end{array}$ & $\begin{array}{c}\text { Ves- } \\
\text { tuário }\end{array}$ & $\begin{array}{l}\text { Trans- } \\
\text { porte }\end{array}$ & $\begin{array}{l}\text { Higie- } \\
\text { ne }\end{array}$ & Saúde & $\begin{array}{c}\text { Educa- } \\
\text { ção }\end{array}$ \\
\hline Até $2 \mathrm{SM}$ & 181,43 & 130,46 & 36,21 & 73,18 & 17,06 & 37,61 & 6,36 \\
\hline $\begin{array}{l}\text { Mais de } 2 \text { a } \\
3 \mathrm{SM}\end{array}$ & 246,38 & 173,26 & 52,70 & 145,91 & 24,78 & 63,16 & 10,45 \\
\hline $\begin{array}{l}\text { Mais de } 3 \text { a } \\
5 \mathrm{SM}\end{array}$ & 330,23 & 239,02 & 83,23 & 250,09 & 37,60 & 96,87 & 22,42 \\
\hline $\begin{array}{l}\text { Mais de } 5 \text { a } \\
6 \mathrm{SM}\end{array}$ & 385,92 & 282,65 & 115,27 & 354,58 & 47,88 & 111,65 & 42,57 \\
\hline $\begin{array}{l}\text { Mais de } 6 \text { a } \\
8 \text { SM }\end{array}$ & 456,65 & 385,36 & 145,47 & 475,85 & 52,71 & 178,41 & 48,06 \\
\hline $\begin{array}{l}\text { Mais de } 8 \text { a } \\
10 \mathrm{SM}\end{array}$ & 500,89 & 459,68 & 167,19 & 732,01 & 67,82 & 194,10 & 66,21 \\
\hline $\begin{array}{l}\text { Mais de } 10 \text { a } \\
15 \mathrm{SM}\end{array}$ & 629,01 & 526,93 & 191,96 & 842,06 & 81,35 & 250,40 & 126,14 \\
\hline $\begin{array}{l}\text { Mais de } 15 \text { a } \\
20 \text { SM }\end{array}$ & 742,32 & 802,54 & 295,56 & $1.255,79$ & 101,73 & 357,14 & 223,77 \\
\hline $\begin{array}{l}\text { Mais de } 20 \text { a } \\
30 \mathrm{SM}\end{array}$ & 904,66 & $1.033,64$ & 367,84 & $1.620,22$ & 123,57 & 470,01 & 296,46 \\
\hline $\begin{array}{l}\text { Mais de } 30 \\
\text { SM }\end{array}$ & $1.088,45$ & $1.386,30$ & 674,98 & $2.911,38$ & 155,09 & 579,46 & 275,01 \\
\hline Média & 415,64 & 359,63 & 133,29 & 495,79 & 50,69 & 152,78 & 60,30 \\
\hline $\begin{array}{l}\text { Classes de } \\
\text { Renda Fa- } \\
\text { miliar (em } \\
\text { SM) }\end{array}$ & $\begin{array}{l}\text { Recrea- } \\
\text { ção }\end{array}$ & Fumo & $\begin{array}{l}\text { Ser- } \\
\text { viços } \\
\text { pes- } \\
\text { soais }\end{array}$ & $\begin{array}{l}\text { Des- } \\
\text { pesas } \\
\text { Diver- } \\
\text { sas }\end{array}$ & $\begin{array}{c}\text { Outras } \\
\text { des- } \\
\text { pesas } \\
\text { cor- } \\
\text { rentes }\end{array}$ & $\begin{array}{l}\text { Au- } \\
\text { mento } \\
\text { do Ati- } \\
\text { vo }\end{array}$ & $\begin{array}{l}\text { Dimi- } \\
\text { nuição } \\
\text { do } \\
\text { passivo }\end{array}$ \\
\hline Até 2 SM & 9,91 & 10,96 & 4,59 & 17,97 & 30,77 & 20,73 & 8,32 \\
\hline $\begin{array}{l}\text { Mais de } 2 \text { a } \\
3 \mathrm{SM}\end{array}$ & 15,43 & 12,69 & 7,19 & 24,68 & 60,92 & 27,49 & 14,77 \\
\hline $\begin{array}{l}\text { Mais de } 3 \text { a } \\
5 \mathrm{SM}\end{array}$ & 25,34 & 15,09 & 12,22 & 39,51 & 104,22 & 41,62 & 29,70 \\
\hline $\begin{array}{l}\text { Mais de } 5 \text { a } \\
6 \mathrm{SM}\end{array}$ & 36,20 & 13,48 & 16,65 & 42,79 & 155,28 & 97,94 & 45,19 \\
\hline $\begin{array}{l}\text { Mais de } 6 \text { a } \\
8 \mathrm{SM}\end{array}$ & 43,26 & 15,24 & 21,59 & 70,52 & 213,78 & 139,14 & 52,81 \\
\hline
\end{tabular}


conclusão.

\begin{tabular}{l|c|c|c|c|c|c|c}
\hline $\begin{array}{l}\text { Classes de } \\
\text { Renda Fa- } \\
\text { miliar (em } \\
\text { SM) }\end{array}$ & $\begin{array}{c}\text { Recrea- } \\
\text { ção }\end{array}$ & Fumo & $\begin{array}{c}\text { Ser- } \\
\text { viços } \\
\text { pes- } \\
\text { soais }\end{array}$ & $\begin{array}{c}\text { Des- } \\
\text { pesas } \\
\text { Diver- } \\
\text { sas }\end{array}$ & $\begin{array}{c}\text { Outras } \\
\text { des- } \\
\text { pesas } \\
\text { cor- } \\
\text { rentes }\end{array}$ & $\begin{array}{c}\text { Au- } \\
\text { mento } \\
\text { do Ati- } \\
\text { vo }\end{array}$ & $\begin{array}{c}\text { Dimi- } \\
\text { nuição } \\
\text { do } \\
\text { passivo }\end{array}$ \\
\hline $\begin{array}{l}\text { Mais de 8 a } \\
\text { 10 SM }\end{array}$ & 64,73 & 10,75 & 27,49 & 99,36 & 374,19 & 309,00 & 67,28 \\
$\begin{array}{l}\text { Mais de 10 a } \\
\text { 15 SM }\end{array}$ & 86,91 & 13,84 & 37,64 & 145,96 & 460,06 & 513,71 & 89,06 \\
$\begin{array}{l}\text { Mais de 15 a } \\
\text { 20 SM }\end{array}$ & 121,81 & 12,55 & 59,32 & 174,30 & 710,05 & 673,28 & 151,56 \\
$\begin{array}{l}\text { Mais de 20 a } \\
\text { 30 SM }\end{array}$ & 157,94 & 13,78 & 81,63 & 283,46 & 1124,27 & $1.002,52$ & 220,12 \\
$\begin{array}{l}\text { Mais de 30 } \\
\text { SM }\end{array}$ & 228,93 & 14,69 & 94,51 & 664,53 & 2473,32 & $2.421,42$ & 263,14 \\
\hline \begin{tabular}{l} 
Média \\
\hline
\end{tabular}
\end{tabular}

Fonte: Elaboração própria com base nos microdados da POF de 2008-2009 (IBGE, 2009).

Notas: ${ }^{(1)}$ Seguindo a data de referência da POF de 2008-2009 (IBGE, 2009), considerou-se o salário mínimo de $R \$ 415$, vigente em 15 de janeiro de 2009.

Na Tabela 5 é apresentado o percentual da renda familiar que as famílias utilizam para adquirir os grupos de despesa selecionados. No primeiro estrato de renda, o gasto com alimentação e habitação compromete $54,80 \%$ do rendimento das famílias. Para as famílias com renda entre $2 \mathrm{SM}$ e 3SM, o dispêndio com esses itens representa $40,30 \%$ da renda. Há uma concentração dos gastos dos mais pobres nesses dois grupos de produtos.

O grupo de despesa transporte é o que tem a maior participação na renda média das famílias do Sul do Brasil, 16,16\%. O percentual da renda familiar despendido com os grupos alimentos, higiene e fumo diminui invariavelmente conforme a renda aumenta.

Ao analisar as Tabelas 4 e 5 conjuntamente, constata-se que as famílias com menor poder aquisitivo gastam, em termos absolutos, menos do que as famílias mais ricas com os grupos de despesa selecionados, mas a participação das despesas na renda das famílias dos primeiros estratos é maior se comparada às famílias dos estratos mais elevados. 
Tabela 5 - Região Sul do Brasil: percentual da renda familiar utilizado na aquisição dos grupos de despesa, segundo as classes selecionadas (em \%)

\begin{tabular}{|c|c|c|c|c|c|c|c|}
\hline $\begin{array}{l}\text { Classes de Renda } \\
\text { Familiar (em SM) } \\
\text { (1) }\end{array}$ & $\begin{array}{l}\text { Alimen- } \\
\text { tos }\end{array}$ & $\begin{array}{l}\text { Habi- } \\
\text { tação }\end{array}$ & $\begin{array}{l}\text { Vestu- } \\
\text { ário }\end{array}$ & $\begin{array}{l}\text { Trans- } \\
\text { porte }\end{array}$ & $\begin{array}{l}\text { Higie- } \\
\text { ne }\end{array}$ & $\begin{array}{l}\text { Saú- } \\
\text { de }\end{array}$ & $\begin{array}{l}\text { Edu- } \\
\text { cação }\end{array}$ \\
\hline Até 2 SM & 31,88 & 22,92 & 6,36 & 12,86 & 3,00 & 6,61 & 1,12 \\
\hline Mais de 2 a 3 SM & 23,66 & 16,64 & 5,06 & 14,01 & 2,38 & 6,06 & 1,00 \\
\hline Mais de 3 a 5 SM & 20,20 & 14,62 & 5,09 & 15,30 & 2,30 & 5,93 & 1,37 \\
\hline Mais de 5 a 6 SM & 16,90 & 12,37 & 5,05 & 15,52 & 2,10 & 4,89 & 1,86 \\
\hline Mais de 6 a 8 SM & 15,95 & 13,46 & 5,08 & 16,62 & 1,84 & 6,23 & 1,68 \\
\hline Mais de 8 a 10 SM & 13,54 & 12,42 & 4,52 & 19,78 & 1,83 & 5,25 & 1,79 \\
\hline Mais de 10 a 15 SM & 12,49 & 10,46 & 3,81 & 16,71 & 1,61 & 4,97 & 2,50 \\
\hline Mais de 15 a $20 \mathrm{SM}$ & 10,43 & 11,27 & 4,15 & 17,64 & 1,43 & 5,02 & 3,14 \\
\hline Mais de 20 a $30 \mathrm{SM}$ & 9,14 & 10,44 & 3,72 & 16,37 & 1,25 & 4,75 & 2,99 \\
\hline Mais de $30 \mathrm{SM}$ & 5,50 & 7,00 & 3,41 & 14,71 & 0,78 & 2,93 & 1,39 \\
\hline Média & 13,55 & 11,72 & 4,34 & 16,16 & 1,65 & 4,98 & 1,97 \\
\hline $\begin{array}{l}\text { Classes de Renda } \\
\text { Familiar (em SM) } \\
\text { (1) }\end{array}$ & $\begin{array}{l}\text { Recrea- } \\
\text { ção }\end{array}$ & Fumo & $\begin{array}{l}\text { Ser- } \\
\text { viços } \\
\text { pesso- } \\
\text { ais }\end{array}$ & $\begin{array}{l}\text { Des- } \\
\text { pesas } \\
\text { Diver- } \\
\text { sas }\end{array}$ & $\begin{array}{l}\text { Ou- } \\
\text { tras } \\
\text { des- } \\
\text { pesas }\end{array}$ & $\begin{array}{l}\text { Au- } \\
\text { men- } \\
\text { to do } \\
\text { Ativo }\end{array}$ & $\begin{array}{c}\text { Dimi- } \\
\text { nui- } \\
\text { ção } \\
\text { do } \\
\text { passi- } \\
\text { vo }\end{array}$ \\
\hline Até 2 SM & 1,74 & 1,93 & 0,81 & 3,16 & 5,41 & 3,64 & 1,46 \\
\hline Mais de 2 a 3 SM & 1,48 & 1,22 & 0,69 & 2,37 & 5,85 & 2,64 & 1,42 \\
\hline Mais de 3 a 5 SM & 1,55 & 0,92 & 0,75 & 2,42 & 6,38 & 2,55 & 1,82 \\
\hline Mais de 5 a 6 SM & 1,58 & 0,59 & 0,73 & 1,87 & 6,80 & 4,29 & 1,98 \\
\hline Mais de 6 a 8 SM & 1,51 & 0,53 & 0,75 & 2,46 & 7,47 & 4,86 & 1,84 \\
\hline Mais de 8 a 10 SM & 1,75 & 0,29 & 0,74 & 2,69 & 10,11 & 8,35 & 1,82 \\
\hline Mais de 10 a $15 \mathrm{SM}$ & 1,73 & 0,27 & 0,75 & 2,90 & 9,13 & 10,20 & 1,77 \\
\hline Mais de 15 a $20 \mathrm{SM}$ & 1,71 & 0,18 & 0,83 & 2,45 & 9,97 & 9,46 & 2,13 \\
\hline Mais de 20 a 30 SM & 1,60 & 0,14 & 0,82 & 2,86 & 11,36 & 10,13 & 2,22 \\
\hline Mais de $30 \mathrm{SM}$ & 1,16 & 0,07 & 0,48 & 3,36 & 12,49 & 12,23 & 1,33 \\
\hline Média & 1,54 & 0,44 & 0,71 & 2,71 & 9,14 & 7,76 & 1,78 \\
\hline
\end{tabular}

Fonte: Elaboração própria com base nos microdados da POF de 2008-2009 (IBGE, 2009).

Nota: ${ }^{(1)}$ Seguindo a data de referência da POF de 2008-2009 (IBGE, 2009), considerou-se o salário mínimo de $\mathrm{R} \$ 415$, vigente em 15 de janeiro de 2009. 
As alíquotas médias dos tributos indiretos por grupo de despesa e por classes de renda selecionadas são apresentadas na Tabela 6. Os grupos que apresentaram a maior alíquota média entre todas as classes de renda selecionadas foram fumo, $83,76 \%$, higiene, $37,41 \%$, e transporte, $28,17 \%$. Ressaltando que para o grupo de despesa fumo, a alíquota média elevada se deve a motivos de saúde pública. A menor alíquota média incide sobre o grupo outras despesas correntes, 0,43\%.

Tabela 6 - Região Sul do Brasil: alíquota média dos tributos indiretos por despesa, segundo as classes selecionadas (em \%)

\begin{tabular}{|c|c|c|c|c|c|c|c|}
\hline $\begin{array}{l}\text { Classes de Ren- } \\
\text { da Familiar (em } \\
\text { SM) }{ }^{(1)}\end{array}$ & $\begin{array}{c}\text { Ali- } \\
\text { mentos }\end{array}$ & $\begin{array}{l}\text { Habi- } \\
\text { tação }\end{array}$ & $\begin{array}{l}\text { Vestu- } \\
\text { ário }\end{array}$ & $\begin{array}{l}\text { Trans- } \\
\text { porte }\end{array}$ & $\begin{array}{l}\text { Higie- } \\
\text { ne }\end{array}$ & Saúde & $\begin{array}{l}\text { Edu- } \\
\text { cação }\end{array}$ \\
\hline Até $2 \mathrm{SM}$ & 15,00 & 19,71 & 24,85 & 21,93 & 34,91 & 20,80 & 16,90 \\
\hline Mais de 2 a 3 SM & 15,55 & 19,47 & 24,77 & 25,24 & 35,92 & 18,62 & 14,74 \\
\hline Mais de 3 a 5 SM & 16,25 & 19,55 & 24,87 & 27,10 & 37,09 & 18,04 & 10,51 \\
\hline Mais de 5 a 6 SM & 16,54 & 20,52 & 25,34 & 28,23 & 38,98 & 18,56 & 9,97 \\
\hline Mais de 6 a 8 SM & 17,10 & 19,14 & 25,01 & 27,83 & 37,46 & 16,32 & 9,72 \\
\hline $\begin{array}{l}\text { Mais de } 8 \text { a } 10 \\
\text { SM }\end{array}$ & 17,31 & 17,21 & 25,12 & 29,23 & 37,57 & 15,18 & 8,82 \\
\hline $\begin{array}{l}\text { Mais de } 10 \text { a } 15 \\
\text { SM }\end{array}$ & 17,60 & 17,44 & 25,48 & 28,57 & 37,53 & 14,60 & 7,86 \\
\hline $\begin{array}{l}\text { Mais de } 15 \text { a } 20 \\
\text { SM }\end{array}$ & 17,78 & 16,53 & 25,87 & 28,84 & 38,64 & 13,89 & 7,50 \\
\hline $\begin{array}{l}\text { Mais de } 20 \text { a } 30 \\
\text { SM }\end{array}$ & 17,56 & 16,24 & 25,53 & 28,05 & 38,18 & 13,39 & 7,73 \\
\hline Mais de $30 \mathrm{SM}$ & 17,60 & 15,64 & 25,72 & 29,34 & 36,65 & 14,95 & 7,66 \\
\hline Média & 16,84 & 18,09 & 25,29 & 28,17 & 37,41 & 15,99 & 8,69 \\
\hline $\begin{array}{l}\text { Classes de Ren- } \\
\text { da Familiar (em } \\
\text { SM) }\end{array}$ & $\begin{array}{l}\text { Recrea- } \\
\text { ção }\end{array}$ & Fumo & $\begin{array}{l}\text { Ser- } \\
\text { viços } \\
\text { pesso- } \\
\text { ais }\end{array}$ & $\begin{array}{l}\text { Despe- } \\
\text { sas Di- } \\
\text { versas }\end{array}$ & $\begin{array}{c}\text { Outras } \\
\text { despe- } \\
\text { sas }\end{array}$ & $\begin{array}{l}\text { Au- } \\
\text { men- } \\
\text { to do } \\
\text { Ativo }\end{array}$ & $\begin{array}{l}\text { Dimi- } \\
\text { nui- } \\
\text { ção do } \\
\text { passi- } \\
\text { vo }\end{array}$ \\
\hline Até $2 \mathrm{SM}$ & 24,50 & 81,21 & 8,65 & 14,31 & 0,23 & 9,48 & 4,49 \\
\hline Mais de 2 a 3 SM & 21,37 & 83,19 & 8,65 & 13,33 & 0,23 & 9,72 & 5,16 \\
\hline Mais de 3 a 5 SM & 20,75 & 84,06 & 8,65 & 13,02 & 0,37 & 11,30 & 4,42 \\
\hline Mais de 5 a 6 SM & 21,98 & 83,58 & 8,65 & 13,61 & 0,35 & 9,05 & 4,80 \\
\hline Mais de 6 a 8 SM & 21,03 & 83,78 & 8,66 & 13,37 & 0,60 & 6,14 & 4,79 \\
\hline $\begin{array}{l}\text { Mais de } 8 \text { a } 10 \\
\text { SM }\end{array}$ & 19,23 & 84,35 & 8,85 & 11,92 & 0,54 & 3,93 & 4,55 \\
\hline
\end{tabular}


conclusão.

\begin{tabular}{l|c|c|c|c|c|c|c}
\hline $\begin{array}{l}\text { Classes de Ren- } \\
\text { da Familiar (em } \\
\text { SM) }\end{array}$ & $\begin{array}{c}\text { (1) } \\
\text { Recrea- } \\
\text { ção }\end{array}$ & Fumo & $\begin{array}{c}\text { Ser- } \\
\text { viços } \\
\text { pesso- } \\
\text { ais }\end{array}$ & $\begin{array}{c}\text { Despe- } \\
\text { sas Di- } \\
\text { versas }\end{array}$ & $\begin{array}{c}\text { Outras } \\
\text { despe- } \\
\text { sas }\end{array}$ & $\begin{array}{c}\text { Au- } \\
\text { men- } \\
\text { to do } \\
\text { Ativo }\end{array}$ & $\begin{array}{c}\text { Dimi- } \\
\text { nui- } \\
\text { ção do } \\
\text { passi- } \\
\text { vo }\end{array}$ \\
\hline $\begin{array}{l}\text { Mais de 10 a 15 } \\
\text { SM }\end{array}$ & 18,63 & 84,80 & 8,65 & 12,89 & 0,48 & 4,16 & 5,54 \\
$\begin{array}{l}\text { Mais de 15 a 20 } \\
\text { SM }\end{array}$ & 18,94 & 84,94 & 8,71 & 12,33 & 0,45 & 3,16 & 6,44 \\
$\begin{array}{l}\text { Mais de 20 a 30 } \\
\text { SM }\end{array}$ & 17,97 & 85,36 & 8,66 & 12,21 & 0,46 & 7,32 & 4,48 \\
Mais de 30 SM & 18,59 & 85,43 & 8,65 & 11,64 & 0,34 & 2,46 & 2,73 \\
\hline Média & 19,72 & 83,76 & 8,67 & 12,58 & 0,43 & 4,78 & 4,72 \\
\hline
\end{tabular}

Fonte: Elaboração própria com base nos microdados da POF de 2008-2009 (IBGE, 2009) em conjunto com a Legislação Tributária.

Nota: ${ }^{(1)}$ Seguindo a data de referência da POF de 2008-2009 (IBGE, 2009), considerou-se o salário mínimo de $R \$ 415$, vigente em 15 de janeiro de 2009.

De acordo com a Tabela 7, a maior carga tributária expressa como porcentagem da renda familiar é de 5,78\%, e incide sobre as famílias com renda de mais 8SM a 10SM para o grupo de despesa transporte.

Tabela 7 - Região Sul do Brasil: Carga tributária indireta por grupos de despesa selecionados expressa como porcentagem da renda familiar, segundo as classes de renda selecionadas (em \%)

\begin{tabular}{|c|c|c|c|c|c|c|c|}
\hline $\begin{array}{l}\text { Classes de Ren- } \\
\text { da Familiar (em } \\
\text { SM) }\end{array}$ & $\begin{array}{l}\text { Ali- } \\
\text { mentos }\end{array}$ & $\begin{array}{l}\text { Habi- } \\
\text { tação }\end{array}$ & $\begin{array}{l}\text { Vestu- } \\
\text { ário }\end{array}$ & $\begin{array}{l}\text { Trans- } \\
\text { porte }\end{array}$ & $\begin{array}{l}\text { Higie- } \\
\text { ne }\end{array}$ & Saúde & $\begin{array}{l}\text { Edu- } \\
\text { cação }\end{array}$ \\
\hline Até $2 \mathrm{SM}$ & 4,78 & 4,52 & 1,58 & 2,82 & 1,05 & 1,37 & 0,19 \\
\hline Mais de 2 a 3 SM & 3,68 & 3,24 & 1,25 & 3,54 & 0,85 & 1,13 & 0,15 \\
\hline Mais de 3 a 5 SM & 3,28 & 2,86 & 1,27 & 4,15 & 0,85 & 1,07 & 0,14 \\
\hline Mais de 5 a 6 SM & 2,79 & 2,54 & 1,28 & 4,38 & 0,82 & 0,91 & 0,19 \\
\hline Mais de 6 a 8 SM & 2,73 & 2,58 & 1,27 & 4,62 & 0,69 & 1,02 & 0,16 \\
\hline Mais de 8 a 10 SM & 2,34 & 2,14 & 1,13 & 5,78 & 0,69 & 0,80 & 0,16 \\
\hline $\begin{array}{l}\text { Mais de } 10 \text { a } 15 \\
\text { SM }\end{array}$ & 2,20 & 1,82 & 0,97 & 4,78 & 0,61 & 0,73 & 0,20 \\
\hline $\begin{array}{l}\text { Mais de } 15 \text { a } 20 \\
\text { SM }\end{array}$ & 1,85 & 1,86 & 1,07 & 5,09 & 0,55 & 0,70 & 0,24 \\
\hline $\begin{array}{l}\text { Mais de } 20 \text { a } 30 \\
\text { SM }\end{array}$ & 1,60 & 1,70 & 0,95 & 4,59 & 0,48 & 0,64 & 0,23 \\
\hline Mais de $30 \mathrm{SM}$ & 0,97 & 1,09 & 0,88 & 4,31 & 0,29 & 0,44 & 0,11 \\
\hline Média & 2,28 & 2,12 & 1,10 & 4,55 & 0,62 & 0,80 & 0,17 \\
\hline
\end{tabular}


conclusão.

\begin{tabular}{|c|c|c|c|c|c|c|c|}
\hline $\begin{array}{l}\text { Classes de Ren- } \\
\text { da Familiar (em } \\
\text { SM) }\end{array}$ & $\begin{array}{l}\text { Recre- } \\
\text { ação }\end{array}$ & Fumo & $\begin{array}{l}\text { Ser- } \\
\text { viços } \\
\text { pesso- } \\
\text { ais }\end{array}$ & $\begin{array}{l}\text { Despe- } \\
\text { sas Di- } \\
\text { versas }\end{array}$ & $\begin{array}{l}\text { Outras } \\
\text { despe- } \\
\text { sas }\end{array}$ & $\begin{array}{l}\text { Au- } \\
\text { men- } \\
\text { to do } \\
\text { Ativo }\end{array}$ & $\begin{array}{c}\text { Dimi- } \\
\text { nuição } \\
\text { do } \\
\text { passi- } \\
\text { vo }\end{array}$ \\
\hline Até 2 SM & 0,43 & 1,56 & 0,07 & 0,45 & 0,01 & 0,35 & 0,07 \\
\hline Mais de 2 a 3 SM & 0,32 & 1,01 & 0,06 & 0,32 & 0,01 & 0,26 & 0,07 \\
\hline Mais de 3 a 5 SM & 0,32 & 0,78 & 0,06 & 0,31 & 0,02 & 0,29 & 0,08 \\
\hline Mais de 5 a 6 SM & 0,35 & 0,49 & 0,06 & 0,25 & 0,02 & 0,39 & 0,09 \\
\hline Mais de 6 a 8 SM & 0,32 & 0,45 & 0,07 & 0,33 & 0,04 & 0,30 & 0,09 \\
\hline Mais de 8 a 10 SM & 0,34 & 0,25 & 0,07 & 0,32 & 0,05 & 0,33 & 0,08 \\
\hline $\begin{array}{l}\text { Mais de } 10 \text { a } 15 \\
\text { SM }\end{array}$ & 0,32 & 0,23 & 0,06 & 0,37 & 0,04 & 0,42 & 0,10 \\
\hline $\begin{array}{l}\text { Mais de } 15 \text { a } 20 \\
\text { SM }\end{array}$ & 0,32 & 0,15 & 0,07 & 0,30 & 0,05 & 0,30 & 0,14 \\
\hline $\begin{array}{l}\text { Mais de } 20 \text { a } 30 \\
\text { SM }\end{array}$ & 0,29 & 0,12 & 0,07 & 0,35 & 0,05 & 0,74 & 0,10 \\
\hline Mais de 30 SM & 0,21 & 0,06 & 0,04 & 0,39 & 0,04 & 0,30 & 0,04 \\
\hline Média & 0,30 & 0,37 & 0,06 & 0,34 & 0,04 & 0,37 & 0,08 \\
\hline
\end{tabular}

Fonte: Elaboração própria com base nos microdados da POF de 2008-2009 (IBGE, 2009) em conjunto com a Legislação Tributária.

Nota: ${ }^{(1)}$ Seguindo a data de referência da POF de 2008-2009 (IBGE, 2009), considerou-se o salário mínimo de $R \$ 415$, vigente em 15 de janeiro de 2009.

O grupo de despesa alimentos, na média, apresentou a segunda maior porcentagem da renda destinada para o pagamento da carga tributária indireta, $2,28 \%$. Para esse grupo e também para fumo, nota-se uma relação inversa entre a renda e o percentual gasto para o pagamento da carga tributária indireta.

Conforme mostra a Tabela 8 , a carga tributária indireta média sobre a renda familiar per capita é de 13,21\% e tem caráter regressivo de acordo com o índice de Lerman-Yitzhaki, que é igual a -0,1670. Os tributos indiretos contribuem para aumentar a desigualdade de renda entre as famílias da região Sul do Brasil. 
Tabela 8 - Região Sul do Brasil: Carga tributária indireta sobre a renda familiar per capita, por tributo selecionado, segundo as classes selecionadas (em \%)

\begin{tabular}{|c|c|c|c|c|c|c|}
\hline $\begin{array}{l}\text { Classes de renda } \\
\text { familiar per ca- } \\
\text { pita (em SM) }\end{array}$ & $\begin{array}{l}\text { Carga indi- } \\
\text { reta sobre } \\
\text { a renda }\end{array}$ & ICMS & PIS & Cofins & IPI & $\begin{array}{c}\text { Carga } \\
\text { indireta } \\
\text { sobre a } \\
\text { despesa }\end{array}$ \\
\hline Até $1 / 2 \mathrm{SM}$ & 21,28 & 10,41 & 1,34 & 6,14 & 2,88 & 19,38 \\
\hline $\begin{array}{l}\text { Mais de } 1 / 2 \mathrm{SM} \text { a } \\
\text { ISM }\end{array}$ & 17,30 & 8,57 & 1,07 & 4,90 & 2,30 & 19,49 \\
\hline $\begin{array}{l}\text { Mais de } 1 \text { SM a } 1 \text { e } \\
\text { 1/2SM }\end{array}$ & 15,32 & 7,63 & 0,94 & 4,31 & 1,94 & 18,92 \\
\hline $\begin{array}{l}\text { Mais de } 1 / 2 \mathrm{SM} \text { a } \\
2 \mathrm{SM}\end{array}$ & 14,55 & 7,37 & 0,88 & 4,02 & 1,79 & 18,87 \\
\hline $\begin{array}{l}\text { Mais de } 2 \mathrm{SM} \text { a } \\
3 \mathrm{SM}\end{array}$ & 14,35 & 7,09 & 0,87 & 3,96 & 1,84 & 18,01 \\
\hline $\begin{array}{l}\text { Mais de } 3 S M \text { a } 3 \text { e } \\
1 / 2 \text { SM }\end{array}$ & 14,36 & 7,12 & 0,86 & 3,96 & 1,82 & 17,00 \\
\hline $\begin{array}{l}\text { Mais de } 3 \text { e } 1 / 2 \text { SM } \\
\text { a } 4 \text { SM }\end{array}$ & 13,69 & 6,81 & 0,83 & 3,80 & 1,58 & 15,96 \\
\hline $\begin{array}{l}\text { Mais de } 4 \mathrm{SM} \mathrm{a} \\
5 \mathrm{SM}\end{array}$ & 12,38 & 6,19 & 0,75 & 3,41 & 1,41 & 15,77 \\
\hline $\begin{array}{l}\text { Mais de } 5 \mathrm{SM} \mathrm{a} \\
6 \mathrm{SM}\end{array}$ & 14,09 & 6,72 & 0,85 & 3,87 & 1,91 & 16,87 \\
\hline $\begin{array}{l}\text { Mais de } 6 \mathrm{SM} \text { a } \\
8 \mathrm{SM}\end{array}$ & 11,64 & 5,69 & 0,71 & 3,23 & 1,38 & 15,22 \\
\hline $\begin{array}{l}\text { Mais de } 8 \mathrm{SM} \text { a } \\
11 \mathrm{SM}\end{array}$ & 12,50 & 6,22 & 0,74 & 3,40 & 1,59 & 15,54 \\
\hline $\begin{array}{l}\text { Mais de } 11 \mathrm{SM} \text { a } \\
16 \mathrm{SM}\end{array}$ & 8,73 & 4,16 & 0,53 & 2,42 & 1,09 & 13,59 \\
\hline Mais de $16 \mathrm{SM}$ & 8,79 & 4,25 & 0,54 & 2,46 & 1,11 & 13,24 \\
\hline Média & 13,21 & 6,52 & 0,80 & 3,67 & 1,66 & 16,83 \\
\hline $\begin{array}{l}\text { Índice de Lerman } \\
\text { - Yitzhaki }\end{array}$ & $-0,1670$ & $-0,1231$ & $-0,1001$ & $-0,1618$ & $-0,1131$ & $-0,0542$ \\
\hline Índice de Gini ${ }^{(2)}$ & 0,5178 & 0,5077 & 0,5030 & 0,5255 & 0,5024 & 0,5765 \\
\hline
\end{tabular}

Fonte: Elaboração própria com base nos microdados da POF de 2008-2009 (IBGE, 2009).

Notas: ${ }^{(1)}$ Seguindo a data de referência da POF de 2008-2009 (IBGE, 2009), considerou-se o salário mínimo de $R \$ 415$, vigente em 15 de janeiro de 2009; (2) Para a renda familiar per capita o índice de Gini foi calculado seguindo sua ordenação, para cada tributo selecionado o índice de Gini foi calculado com base na ordenação da renda familiar per capita após a dedução do tributo indicado na coluna. 
Dentre os tributos indiretos destacados, o que apresenta maior regressividade é a Cofins, seguido do ICMS, com índices de Lerman-Yitzaki iguais a -0,1618 e $-0,1231$, respectivamente. O tributo indireto menos regressivo é o PIS.

\section{Considerações Finais}

Foi possível observar, no presente trabalho, que os tributos diretos são progressivos na região Sul do Brasil, conforme mostra o índice de Lerman-Yitzhaki. Contudo, o Imposto sobre a Propriedade Predial e Territorial Urbana (IPTU) é regressivo em relação à renda familiar per capita e é um exemplo nítido de que a progressividade da carga tributária direta poderia ser melhorada. O grande problema é que esse é um tributo municipal e depende do poder local para fazer alterações em sua alíquota. Talvez seja o caso de estabelecer uma regulamentação geral sobre os critérios das alíquotas empregadas sobre o valor do imóvel.

Constatou-se também que o tributo que tem maior participação na carga tributária indireta sobre as famílias da região Sul do Brasil é o ICMS. A carga tributária indireta é regressiva, quando tomada tanto a renda como a despesa como base e a Cofins é o tributo com maior regressividade.

Comparando a carga tributária indireta da POF 2002-2003 com da POF 2008-2009, notou-se que, apesar do percentual da renda destinado ao pagamento desse tipo de tributo ter diminuído na maioria dos estratos de renda, a tributação média para a região Sul teve um leve aumento.

É possível perceber, por meio dos resultados obtidos, que uma forma de melhorar a progressividade é reduzir a carga tributária incidente sobre os produtos que comprometem boa parte do orçamento das famílias mais pobres, como é o caso dos alimentos.

\section{Referências}

BRASIL. Ministério da Fazenda. Cartilha sobre a Reforma Tributária. Brasília, DF, 2008. Disponível em: < http://www.fazenda.gov.br/portugues/documentos/2008/fevereiro/CartilhaReforma-Tributaria.pdf> . Acesso em: 02 set. 2012.

. Ministério da Fazenda. Receita federal. Carga Tributária no Brasil - 2013. Brasília, DF: Subsecretaria de Tributação e Contencioso, Receita Federal, 2014. 45 p. Disponível em: $<$ http://idg.receita.fazenda.gov.br/dados/receitadata/estudos-e-tributarios-e-aduaneiros/ estudos-e-estatisticas/carga-tributaria-no-brasil/carga-tributaria-2013.pdf > . Acesso em: 05 set. 2015.

CREEDY, J. Are consumption taxes regressive? The Australian Economic Review, Melbourne, v. 31, n. 2, p. 107-116, 1998. 
HOFFMANN, R. Medindo a regressividade das transferências. In: BARROS, R. P.; FOGUEL, M. N.; ULYSSEA, G. (Org.). Desigualdade de renda no Brasil: uma análise da queda recente. Rio de Janeiro: Ipea, 2007. v. 2. cap. 20. p. 179-195.

Medindo a regressividade das transferências. In: BARROS, R. P.; FOGUEL, M. N.; ULYSSEA, G. (Org.). Desigualdade da distribuição de renda no Brasil: a contribuição de aposentadorias e pensões e de outras parcelas do rendimento domiciliar per capita. Economia e Sociedade, Campinas, v. 18, n. 1(35), p. 213-231, abr. 2009.

IBGE. Pesquisa de Orçamentos Familiares 2008-2009 - Microdados. Rio de Janeiro, 2009. 1 CD-ROM.

LERMAN, R. I.; YITZHAKI, S. Changing ranks and the inequality impacts of taxes and transfers. National Tax Journal, v. 48, n. 1, p. 45-59, Mar. 1995.

PINTOS-PAYERAS, J. A. A carga tributária no Brasil e sua distribuição. 2008. 139 f. Tese (Doutorado em Economia Aplicada) - Escola Superior de Agricultura Luiz de Queiroz, Universidade de São Paulo, Piracicaba, 2008.

. Análise da progressividade da carga tributária sobre a população brasileira. Pesquisa e Planejamento Econômico, v. 40, n. 2, p. 153-186, 2010.

PINTOS-PAYERAS, J. A.; SILVA, D. M; CARVALHO, S. C; Carga tributária sobre alimentos no Paraná. In: ENCONTRO NACIONAL ENABER, 9., 2011, Natal. Anais... Natal: Enaber, 2011. p. 1- 15.

POTERBA, J. M. Lifetime incidence and the distributional burden of excise taxes. The American Economic Review, Nashville, v. 79, n. 2, p. 325-330, May 1989.

Recebido em: 03/10/2013. Aceito em: 12/07/2016. 